\title{
An improved genetic sex test for Atlantic salmon (Salmo salar L.)
}

\author{
R. Andrew King ${ }^{1}\left[\right.$ (]) Jamie R. Stevens ${ }^{1} \mathbb{D}$
}

Received: 18 October 2018 / Accepted: 24 April 2019 / Published online: 30 April 2019

(c) The Author(s) 2019

\begin{abstract}
Accurate determination of sex ratios is an important metric for the conservation and management of wild Atlantic salmon populations. Previously published primers for a male-specific gene were shown to be unreliable at determining sex due to the presence of deletions in the forward primer-binding site. A new forward primer, used in conjunction with the existing reverse primer, greatly improved reliability of the genetic test, correctly assigning gender in samples of known sex. Using DNA extracted from both contemporary and archive tissues, comparison between the two primer sets screened on collections of unknown sex ratio showed significant discrepancies in the number of males identified. The new primer will help improve the management and conservation of Atlantic salmon by providing accurate sex ratios for the setting of Conservation Limits.
\end{abstract}

Keywords Atlantic salmon $\cdot \mathrm{sdY} \cdot$ Genetic sex test $\cdot$ Salmonid management

Knowledge of sex ratios in andromous salmonid species is a key metric for their conservation and management, especially in the setting of Conservation Limits (CLs, White et al. 2016), which defines the minimum number of ova required to ensure healthy, self-sustaining populations. However, accurate determination of sex in salmonids that for the majority of their lives do not display distinguishing secondary sex characteristics has been problematic. Traditionally it has only been possible to determine the sex of juvenile and pre-spawning adult salmon by lethal sampling. Given the recent declines in Atlantic salmon stocks (ICES 2013), such an approach is undesirable. A viable alternative is to use a recently developed molecular technique to detect the presence of the male-specific $s d Y$ (sexually dimorphic on the Y-chromosome) gene (Yano et al. 2013) using scales or finclips as a source of DNA.

Screening of a set of known-sex individuals used in two hatchery programmes with the Yano et al. (2013) primers showed inconsistencies between phenotypic sex and genetic

Electronic supplementary material The online version of this article (https://doi.org/10.1007/s12686-019-01094-y) contains supplementary material, which is available to authorized users.

R. Andrew King

meeg@exeter.ac.uk

1 College of Life and Environmental Sciences, University of Exeter, Hatherly Building, Prince of Wales Road, Exeter EX4 4PS, UK sex. Subsequent investigation showed that the forward primer (SS sdy S) was designed to a region of the first intron of the $s d Y$ gene that is prone to indel mutations (Quéméré et al. 2014). We designed a new primer, located in exon 1 of the $s d Y$ gene [Ss sdy Ex1F-ATGGTTGACAGAGAG GCCAGATTCCAA, used in combination with SS sdy AS (Yano et al. 2013)] and tested it for its ability to improve the reliability of genetic sex determination in Atlantic salmon.

Genomic DNA was extracted from contemporary scales and ethanol preserved adipose finclips following the method of Truett et al. (2000). For archive scales (collected 2004, Table 1) DNA was extracted using Qiagen Blood and Tissue kits. Molecular sexing was undertaken using a duplex Polymerase Chain Reaction (PCR) approach using primers amplifying a portion of the $s d Y$ gene and primers for the fatty acid-binding protein $6 \mathrm{~b}(f a b p 6 b)$ gene (Lai 2007, positive control amplifying on both males and females). Amplifications were performed in a $10 \mu \mathrm{L}$ volume, containing $5 \mu \mathrm{L}$ of HotStar Taq Master Mix Kit (Qiagen), $0.1 \mu \mathrm{M}$ each fabp6b primer and $0.2 \mu \mathrm{M}$ each $s d Y$ primer (SS sdy S-SS sdy AS or Ss sdy Ex1F-SS sdy AS) and $1 \mu \mathrm{L}$ of extracted DNA. For archive scales, amplifications were performed as above except using $2 \mu \mathrm{L}$ of DNA and with the addition of $0.1 \mu \mathrm{L}$ BSA ( $20 \mathrm{mg} / \mathrm{mL}$; bovine serum albumin). PCR cycling conditions were $95^{\circ} \mathrm{C}$ for $5 \mathrm{~min}$, followed by 35 cycles of $94{ }^{\circ} \mathrm{C}$ for $30 \mathrm{~s}, 60^{\circ} \mathrm{C}$ for $30 \mathrm{~s}, 72^{\circ} \mathrm{C}$ for $40 \mathrm{~s}$ and a final extension at $72{ }^{\circ} \mathrm{C}$ for $10 \mathrm{~min}$. The fapd $6 \mathrm{~b}$ primers amplify a product of 457 bp in both sexes, while the SS sdy S-SS sdy AS and 
Table 1 Results of PCR screening of Atlantic salmon samples with the SS sdy S-SS sdy AS and Ss sdy Ex1F-SS sdy AS primer combinations

\begin{tabular}{|c|c|c|c|c|c|c|c|c|c|c|c|c|c|}
\hline & \multirow[t]{2}{*}{ Year } & \multirow[t]{2}{*}{ Tissue } & \multirow[t]{2}{*}{$\mathrm{N}$} & \multicolumn{2}{|c|}{ Known sex } & \multicolumn{4}{|c|}{ SS sdy S-SS sdy AS } & \multicolumn{4}{|c|}{ Ss sdy Ex1F-SS sdy AS } \\
\hline & & & & $\mathrm{N}_{\text {male }}$ & $\mathrm{N}_{\text {female }}$ & $\mathrm{N}_{\text {male }}$ & $\mathrm{N}_{\text {female }}$ & $\mathrm{P}_{\text {male }}$ & $\mathrm{P}_{\text {female }}$ & $\mathrm{N}_{\text {male }}$ & $\mathrm{N}_{\text {female }}$ & $\mathrm{P}_{\text {male }}$ & $\mathrm{P}_{\text {female }}$ \\
\hline River Wye hatchery adults & 2012 & Finclip & 97 & 53 & 44 & 49 & 48 & 0.505 & 0.495 & 53 & 44 & 0.546 & 0.454 \\
\hline River Wye parr & 2011 & Finclip & 92 & - & - & 37 & 55 & 0.402 & 0.598 & 47 & 45 & 0.511 & 0.489 \\
\hline River Tamar hatchery adults & 2010 & Finclip & 15 & 7 & 8 & 7 & 8 & 0.467 & 0.533 & 7 & 8 & 0.467 & 0.533 \\
\hline River Tamar adults & 2016 & Scale & 187 & - & - & 98 & 89 & 0.524 & 0.476 & 112 & 75 & 0.599 & 0.401 \\
\hline River Tamar smolts & 2016 & Finclip & 192 & - & - & 71 & 121 & 0.370 & 0.630 & 84 & 108 & 0.438 & 0.563 \\
\hline River Tamar smolts & 2017 & Finclip & 131 & - & - & 33 & 98 & 0.252 & 0.748 & 40 & 91 & 0.305 & 0.695 \\
\hline Shetland Islands parr & 2015 & Finclip & 42 & - & - & 18 & 24 & 0.429 & 0.571 & 23 & 19 & 0.548 & 0.452 \\
\hline River Fowey parr & 2004 & Scale & 30 & - & - & 8 & 22 & 0.267 & 0.733 & 11 & 19 & 0.367 & 0.633 \\
\hline
\end{tabular}

\begin{abstract}
Wye adult (6E217D3) GTTATCTAAGAGTGTTTTGATTTTCATTATTTTGGGCCTATGCATTTCTGATGTTGAACAGCTTAAGGACTGTGTC Wye adult (69C260C) GTTATCTAAGAGTGTTTTGATTTTCATTATTTTGGGCCTATGCATTTCTGATGTTGAACAGCTTAAGGACTGTGTC Wye adult (69C42D4) GTTATCTAAGAGTGTTTTGATTTTCATTATTTTGGGCCTATGCATTTCTGATG--------CTTAAGGACTGTGTC Wye adult (6B3C437) GTTATCTAAGAGTGTTTTGATTTTCATTATTTTGGGCCTATGCATTTCTGATG--------CTTAAGGACTGTGTC Tamar smolt 05 GTTATCTAAGAGTGTTTTGATTTTCATTATTTTGGGCCTATGCATTTCTGATGTTGAACAGCTTAAGGACTGTGTC Tamar smolt 16 GTTATCTAAGAGTGTTTTGATTTTCATTATTTTGGGCCTATGCATTTCTGATGTTGAACAGCTTAAGGACTGTGTC Tamar smolt $\mathbf{5 8}$ GTTATCTAAGAGTGTTTTGATTTTCATTATTTTGGGCCTATGCATTTCTGATG---AACAGCTTAAGGACTGTGTC Tamar smolt $\mathbf{7 3}$ GTTATCTAAGAGTGTTTTGATTTTCATTATTTTGGGCCTATGCATTTCTGATG---AACAGCTTAAGGACTGTGTC SS sdy S primer GGCCTATGCATTTCTGATGTTGA
\end{abstract}

Fig. 1 Partial sequence for intron 1 of the Atlantic salmon sexually dimorphic on the Y-chromosome $(s d Y)$ gene for four River Wye hatchery adult males and four River Tamar male salmon smolts. Sequence for the SS sdy S primer (Yano et al. 2013) is included for comparison

Ss sdy Ex1F-SS sdy AS combinations amplify products of 563-667 bp and 651-755 bp, respectively in male fish only. Products were visualised on ethidium bromide-stained $1.5 \%$ agarose gels (Figs. S1 and S2). A negative control (wateronly template) and two positive controls (DNA from known male and female salmon) were included in each batch of amplifications.

For DNA sequencing, PCR products from eight male fish were purified using $0.25 \mathrm{U}$ each of Exonuclease I and Antarctic Phosphatase (both New England Biolabs) incubated at $37{ }^{\circ} \mathrm{C}$ for $45 \mathrm{~min}$ and $80{ }^{\circ} \mathrm{C}$ for $15 \mathrm{~min}$. Products were sequenced in the forward direction using the Ss sdy Ex1F primer on a 3730xl Genetic Analyzer (Applied Biosystems) by EUROFINS (Ebersberg, Germany).

Sequencing revealed that the cause of the failure of the SS sdy S-SS sdy AS primer combination to detect all male fish was due to deletion mutations at the $3^{\prime}$ region of the primer-binding site within the first intron of the sdy gene (Figs. 1, S3). Two separate deletions resulted in the failure of annealing of the SS sdy S primer. Screening of hatchery samples with the two primer pairs showed that the original Yano et al. (2013) primers were not detecting all the males known to be in the sample, whereas all fish were sexed correctly using the new Ss sdy Ex1 F primer (Table 1). In collections were the sex ratio was not initially known, the discrepancy between the two sets of primers was as much as $12 \%$, a difference that could dramatically affect the level of Conservation Limits, with the original Yano et al. primer pair falsely exaggerating the number of female fish present.

The new primer described here improves the reliability of genetic sex testing in Atlantic salmon resulting in more accurate determination of sex ratios without having to resort to lethal sampling. The primers work equally well on both fresh and archive samples and can be used to help manage and conserve dwindling stocks and to track temporal changes in sex ratios across all life history stages of Atlantic salmon.

Acknowledgements This research was funded by the European Union Interreg France England Channel programme project 'Salmonid Management Around the Channel' (SAMARCH), with additional funding from the UK Department of Environment, Farming and Rural Affairs (DEFRA). We thank Simon Toms (Environment Agency) and Peter Gough (Natural Resources Wales) for co-ordinating the collection of samples from the River Tamar and River Wye, respectively.

Open Access This article is distributed under the terms of the Creative Commons Attribution 4.0 International License (http://creativeco mmons.org/licenses/by/4.0/), which permits unrestricted use, distribution, and reproduction in any medium, provided you give appropriate credit to the original author(s) and the source, provide a link to the Creative Commons license, and indicate if changes were made. 


\section{References}

ICES (2013) Report of the Working Group on North Atlantic Salmon (WGNAS). 3-12 April 2013, Copenhagen, Denmark. ICES CM 2013/ACOM: 09, $380 \mathrm{p}$

Lai YY (2007) Evolution and characterization of fatty acid-binding proteins (fabps) in Atlantic salmon (Salmo salar). Unpublished $\mathrm{PhD}$ thesis, Simon Fraser University, Canada

Quéméré E, Perrier C, Besnard A-L, Evanno G, Bagliniere J-L, Guigen Y, Launey S (2014) An improved PCR-based method for faster sex determination in brown trout (Salmo trutta) and Atlantic salmon (Salmo salar). Conserv Genet Resour 6:825-827

Truett GE, Heeger P, Mynatt RL, Truett AA, Walker JA, Warman ML (2000) Prepartion of PCR-quality mouse genomic DNA with sodium hydroxide and TRIS (HotSHOT). Biotechniques 29:52-54
White J, Ó Maoiléidigh N, Gargan P, de Eyto E, Chaput G, Roche W, McGinnity P, Crozier WW, Boylan P, Doherty D, O'Higgins K, Kennedy B, Lawler I, Lyons D, Marnell (2016) Incorporating natural variability in biological reference points and population dynamics into management of Atlantic salmon (Salmo salar L.) stocks returning to home waters. ICES J Mar Sci 73:1513-1524

Yano A, Nicol B, Jouanno E, Quillet E, Fostier A, Guyomard R, Guiguen Y (2013) The sexually dimorphic on the Y-chromosome gene $(s d Y)$ is a conserved male-specific Y-chromosome sequence in many salmonids. Evol Appl 6:486-496

Publisher's Note Springer Nature remains neutral with regard to jurisdictional claims in published maps and institutional affiliations. 